\title{
Análise de Sentimento no Contexto de Comentários a Projetos de Lei Relativos à Transparência
}

\author{
Roxana Lisette Quintanilla Portugal, Julio Cesar Sampaio do Prado Leite \\ Departamento de Informática, PUC-Rio, Rio de Janeiro, Brasil \\ \{rportugal, julio\}@inf.puc-rio.br
}

\begin{abstract}
In 2016, Engiel et al. found 10 bills highly related to transparency, using text mining driven by a transparency knowledge base, on the VotenaWeb site. In 2017, Portugal et al. text-mined comments on these 10 bills, in 164 of these comments, 6 bills were found to have a tendency or demand for transparency. The present work explores the comments from another perspective; we wanted to explore sentiment analysis to know the most negative comments by using the SentiStrength tool. As a result, of the 164 comments 60 were classified to be very negative, however, its accuracy is not a good one when dealing with the set of comments from citizens who approve the bills. We detailed a qualitative analysis of these comments with respect to the tool result.
\end{abstract}

Resumo. Em 2016, Engiel et al. encontraram 10 projetos de lei, altamente relacionados à transparência, usando técnicas de mineração de texto e uma base de conhecimento sobre Transparência. Em 2017, Portugal et al. usaram os comentários feitos sobre os 10 projetos de lei; dos 164 comentários, 6 projetos foram identificados com uma tendência ou demanda por transparência. O trabalho de 2018 explora os comentários a partir de outra perspectiva, nós queremos saber quais são os comentários mais negativos usando análise de sentimentos, através da ferramenta SentiStrength. Como resultado, dos 164 comentários, 60 foram classificados como muito negativos. No entanto, seu desempenho não é bom quando se lida com o conjunto de comentários dos cidadãos que aprovam os projetos de lei. Uma análise qualitativa é apresentada para esse subconjunto de comentários.

Palavras-Chave: Análise de Sentimento, Transparência, Projetos de Lei, Mineração de texto

\section{Introdução}

Existem vários desafios de como organizar grande volume de dados, sendo um deles a análise de comentários na mídia. A partir do ponto de vista da transparência, essas análises de comentários constituem uma oportunidade para procurar descobrir o que o cidadão está demandando.

Um corpus de comentários amplamente usado para a análise de sentimentos é o Twitter. O qual, pelas suas características de comentários pequenos e textos escritos de maneira informal, exige heurísticas mais elaboradas, além da classificação por polaridade, de comentários negativos ou positivos. No entanto, existe a possibilidade de 
um texto ter ambos os sentimentos, assim como alguns serem mais positivos do que outros.

SentiStrength é um trabalho de Thelwall et al. (2012) que têm refinado suas heurísticas para o tratamento de textos curtos e informais. Um exemplo é o tratamento de textos mal escritos intencionalmente, por exemplo: a palavra "mal" expressa um sentimento menos negativo do que "maaal", não obstante, em algoritmos que só determinam a polaridade, isto é considerado como uma falha na escrita e tem um procedimento que corrige a palavra.

Neste trabalho, verificamos os sentimentos expressos em comentários referentes a 8 projetos de lei, do sítio VotenaWeb (2009), relacionados à transparência. O corpus de 164 comentários foi classificado em três categorias: comentários de cidadãos que aprovam, desaprovam, ou que estão indecisos sobre um Projeto de Lei (PL). Os textos cumprem com as caraterísticas para o qual o SentiStrength foi desenvolvido, textos curtos e informais. O principal desafio é verificar o desempenho do SentiStrength usando o léxico em Português que foi publicado pelos autores, no entanto, como um léxico não testado (SentiStrength Tool, 2018).

O trabalho está organizado da seguinte forma. A Seção 2 apresenta os comentários processados, contextualizando-os com a descrição de cada PL (Projeto de Lei). A Seção 3 discute as características da ferramenta utilizada. A Seção 4 relata resultados obtidos face à classificação manual por um dos autores. Concluímos sumarizando os resultados, bem como indicando trabalhos futuros.

\section{Projetos de Lei com indicadores de Transparência}

Em 2016, Engiel et al. identificaram 10 PLs +transparentes por possuírem indicadores de transparência. Essa filtragem foi realizada utilizando técnicas de mineração de texto e conhecimento de transparência, representado em um catálogo SIG (Softgoal Interdependence Graph) Chung et al. (2000). O SIG de transparência do grupo ER-PUC Rio (2013) é uma modelagem de qualidades, que são utilizadas para a identificação de requisitos não funcionais (NFR) de transparência.

Desses 10 PLs, Portugal et al. (2017a, 2017b) descobriram que dois PLs, o PLC 370-2010 e PLV 8-2010 foram selecionados erroneamente.

Tabela 1. 10PL + transparentes (Engiel, 2016)

\begin{tabular}{|l|c|}
\hline \multicolumn{1}{|c|}{ Projeto de Lei } & \% Voto (si) \\
\hline pls-193-2013 & $97 \%$ \\
\hline plc-1080-2011 & $96 \%$ \\
\hline pls-79-2010 & $95 \%$ \\
\hline plc-3497-2015 & $94 \%$ \\
\hline pls-82-2009 & $93 \%$ \\
\hline pls-387-2011 & $92 \%$ \\
\hline plc-3305-2008 & $86 \%$ \\
\hline pls-68-2010 & $72 \%$ \\
\hline ple 370-2010 & $61 \%$ \\
\hline plv-8-2010 & $18 \%$ \\
\hline
\end{tabular}

A Tabela 1, completa (com os projetos riscados), foi apresentada por Engiel et al. (2016) e mostrava a aprovação dos cidadãos sobre os 10 PLs + transparentes no portal Votenaweb. A Tabela 1 foi reordenada segundo o \% de aprovação para facilitar a análise nas Subseções seguintes (2.1 a 2.8). Para cada PL de cada Subseção foi 
consultada, na fonte ${ }^{1}$ do trabalho prévio de Portugal et al. (2017b), quais palavras chaves do catálogo de Transparência que filtraram esse PL, ou seja, o determinante para que a mineração de texto identificasse o referido PL como relacionado à transparência. Para cada Subseção, apresenta-se um trecho do PL, para efeito de contextualização. Para cada Subseção iremos analisar os comentários utilizando o software SentiStrength (2012) de maneira a entender como os comentários a cada PL da Tabela 1 se comporta sob a perspectiva de "sentimento".

A análise do SentiStrength (2012) qualifica o sentimento de um texto tanto na escala: de 1 (positivo) até 5 (extremamente positivo), como na escala de -1 (negativo) até -5 (extremamente negativo). Se um texto tem a mesma qualificação, por exemplo (3, -3), é considerado um texto neutro. Para a análise a seguir, em cada Subseção, filtramos os comentários bem negativos, ou seja, aqueles que o SentiStrength qualifica de -3 até 5. Para cada Subseção, apresenta-se uma tabela com o comentário e as qualificações em ambas escalas (positiva e negativa) dada pela ferramenta.

\subsection{PLS-193-2013}

O PL tem por título: Obrigará a OAB e os outros conselhos profissionais a se submeterem às regras da Lei de Acesso à Informação. Tem 97\% de aprovação dos cidadãos com 3392 votos. A situação atual do projeto é: em tramitação. O PL demanda a qualidade de acessibilidade (ver Fig.1). O PL tem 25 comentários, dos quais, após a análise de sentimentos, 6 foram classificados como bem negativos, ver Tabela 2 .

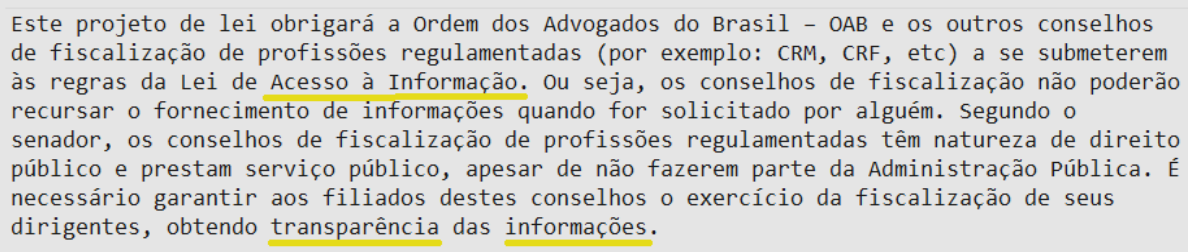

Figura 1. Palavras chaves de transparência no PLS-193-2013

Tabela 2. Análise de Sentimentos nos comentários do PLS-193-2013

\begin{tabular}{|c|c|c|}
\hline Comentários & + & - \\
\hline $\begin{array}{l}\text { Não acho que eles possam se eximir, mas apertar o pescoço dos Conselhos é essencial. Da OAB então, } \\
\text { nem se fala. }\end{array}$ & 1 & -3 \\
\hline Já é assim,não é?: & 1 & -3 \\
\hline $\begin{array}{l}\text { @ Kelly e @ Raphael, porque a OAB, efetivamente, é um orgão que governa a vida dos cidadãos. Não é } \\
\text { governamental, de fato, mas todo advogado é obrigado a ser membro e passar no exame deles, de forma } \\
\text { que funciona como uma agência governamnetal }\end{array}$ & 2 & -3 \\
\hline $\begin{array}{l}\text { Os conselhos profissionais não tem verba pública envolvida então a lei de acesso à informação não se } \\
\text { aplica, se aplica apenas aos profissionais de cada area registrados, estes sim podem solicitar acesso à } \\
\text { informações, o público em geral não tem porque ter acesso às informações, porque um administrador ou } \\
\text { um engenheiro precisa saber das contas da OAB? se quem contribui são os advogados? Os Advogados } \\
\text { sim precisam ter acesso a informações da OAB, engenheiros do CREA e assim por diante. }\end{array}$ & 1 & -3 \\
\hline $\begin{array}{l}\text { Porque a OAB tem que se submeter a lei de acesso a informação, se não recebe nenhum subvenção do } \\
\text { governo? A OAB sobrevive das anuidades dos advogados, e não recebe nenhum centavo do governo. } \\
\text { Portanto, quem tem que pedir a prestação de contas são os próprios advogados. Lei de acesso à } \\
\text { informação é para conselhos de classe que recebem do governo não para a oab. }\end{array}$ & 1 & -3 \\
\hline OAB não é órgão do Estado...Instituição anômala! & 1 & -3 \\
\hline
\end{tabular}

\footnotetext{
${ }^{1}$ https://github.com/nitanilla/Mining-Brazilian-bills-related-to-Tranparency/issues [issues 12, 13]
} 


\subsection{PLC-1080-2011}

O PL tem por título: Obrigará todos os senadores, deputados e vereadores a realizar audiências públicas mensal com o objetivo de prestar informações sobre sua atuação parlamentar, e tem $96 \%$ de aprovação dos cidadãos com 1735 votos. A situação atual do PL é: em tramitação. A Figura 2 aponta as caraterísticas de transparência do PL o qual foi classificado no grupo de PL's que demandam informatividade. Este projeto contém 67 comentários. Tabela 3 apresenta os 12 comentários que foram classificados como bem negativos.

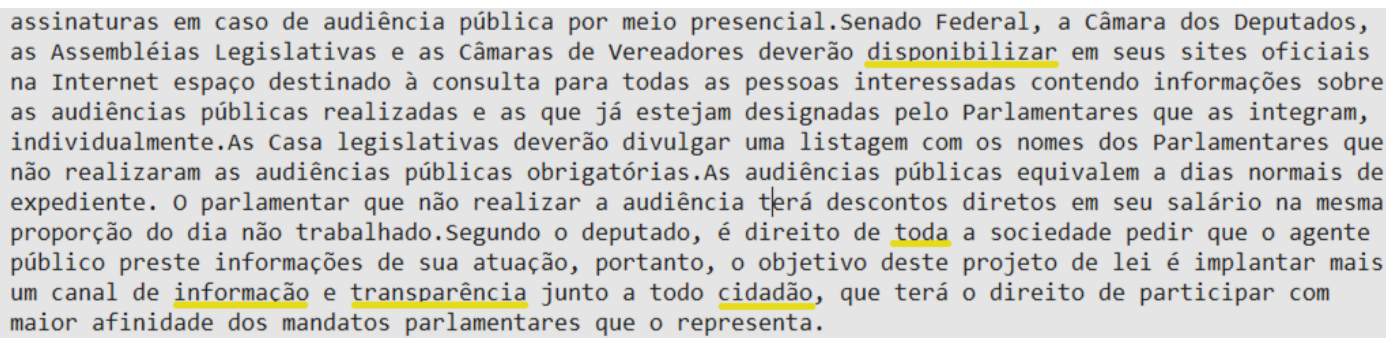

Figura 2. Palavras chaves de transparência no PLC-1080-2011

Tabela 3. Análise de Sentimentos nos comentários do PLC-1080-2011

\begin{tabular}{|c|c|c|}
\hline Comentários & + & - \\
\hline $\begin{array}{l}\text { O eleitor merece um follow up, para confirmar ou não se seu candidato está correspondendo a sua } \\
\text { expectativa. }\end{array}$ & 1 & -4 \\
\hline $\begin{array}{l}\text { Pela lógica deveria prestar contas do seu trabalho, mas ja que isso não acontece seria válido esse } \\
\text { projeto. }\end{array}$ & 1 & -3 \\
\hline $\begin{array}{l}\text { Embora falte lapidar este projeto, pois poderiam agilizar o processo de informação, acredito que será } \\
\text { um passo para diminuirmos o maior câncer deste, ou seja, a Corrupção!!! }\end{array}$ & 1 & -4 \\
\hline Isso poderia ser espontâneo, mas já que não é.... & 1 & -3 \\
\hline $\begin{array}{l}\text { Eles vão fazer as audiências e ainda vão enrolar a gente se a gente deixar. Não adianta o politico } \\
\text { prestar contas se o povo não presta atenção ;) }\end{array}$ & 1 & -3 \\
\hline $\begin{array}{l}\text { voto sim com a pulga atrás da orelha, sabendo que a hora-extra das excelências vale quanto NÃO pesa } \\
\text { e que estão doidos para faturar planilhas-extras de horas-extras através de assessores-extras, } \\
\text { ghostwriters-extras, secretários-extras etcoeteras-extras }\end{array}$ & 1 & -3 \\
\hline $\begin{array}{l}\text { Historinha dele, pois os pelegos vão para a audiência e os canalhas vão aprovar os projetos que os } \\
\text { pelegos apoiaram! Vindo da esquerda, eu não confio! }\end{array}$ & 1 & -3 \\
\hline $\begin{array}{l}\text { Concordo que seja na transparencia pela web mesmo. Onde não haveria custo e todos nós poderiamos } \\
\text { acompanhar. Eles tem que fazer o trabalhos deles. Concordo que se votar sim, seria mais uma perda } \\
\text { de tempo e aumento dos gastos públicos. }\end{array}$ & 1 & -3 \\
\hline $\begin{array}{l}\text { Eles têm assessores para auxiliá-los. E muitos! Não se perderia tempo; seria tempo investido. E não } \\
\text { seria muito tempo. }\end{array}$ & 1 & -3 \\
\hline $\begin{array}{l}\text { Com o voto distrital o representante seria de fato representantes, porque atualmente não é isso que } \\
\text { ocorre, simplesmente votam aquilo que o partido/executivo manda e a população que se dane. } \\
\text { Exemplo: recomposição das aposentadorias do INSS. Governo abocanhou o dinheiros do INSS e } \\
\text { agora está fazendo o mesmo com o FGTS. }\end{array}$ & 1 & -3 \\
\hline $\begin{array}{l}\text { Não sou político, mas acho desnecessário tais audiências. Se alguém tem tempo para isso e deseja } \\
\text { saber o desempenho, propostas e feitos de parlamentares basta comparecer às sessões nas casas } \\
\text { legislativas, ou assistam as TVs. Câmara e Senado. Seria mais um gasto às custas do erário público. }\end{array}$ & 1 & -3 \\
\hline $\begin{array}{l}\text { Prestar contas é obrigação dos políticos. Mas Audiência Pública pra cada um vai ser um gasto público } \\
\text { desnecessário, ainda mais para um público que não acompanha. }\end{array}$ & 1 & -3 \\
\hline
\end{tabular}

\subsection{PLS-79-2010}

O PL com título: Determinará obrigações para a realização de audiências públicas, tem $91 \%$ de aprovação dos usuários com 136 votos. O estado atual do PL é: em tramitação. O PL demanda duas qualidades: acessibilidade e informatividade (ver 
Fig.3). Em tabela 4 se mostra o único comentário de este projeto: quais obrigações?. $O$ comentário foi classificado como neutro.

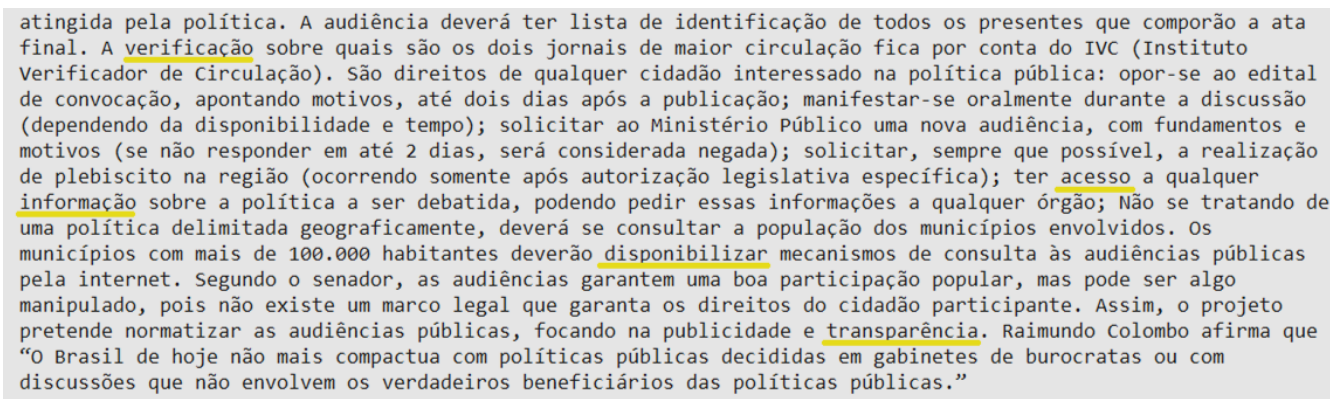

Figura 3. Palavras chaves de transparência no PLS-79-2010

Tabela 4. Análise de Sentimentos no comentário do PLS-79-2010

\begin{tabular}{|l|c|c|}
\hline \multicolumn{1}{|c|}{ Comentários } & + & - \\
\hline Quais obrigações? & 1 & -1 \\
\hline
\end{tabular}

\subsection{PLC-3497-2015}

O PL tem por título: Tornará obrigatória a divulgação, na internet, da folha de pagamento dos funcionários da Administração Pública Direta e Indireta, incluindo adicionais, auxílios e gratificações, e tem 94\% de aprovação dos cidadãos com 2372 votos. A situação atual do PL é: em tramitação. A Fig. 4 mostra que o PL demanda principalmente acessibilidade. Este projeto contém 20 comentários, dentre os quais 6 comentários são bem negativos (ver Tabela 5).

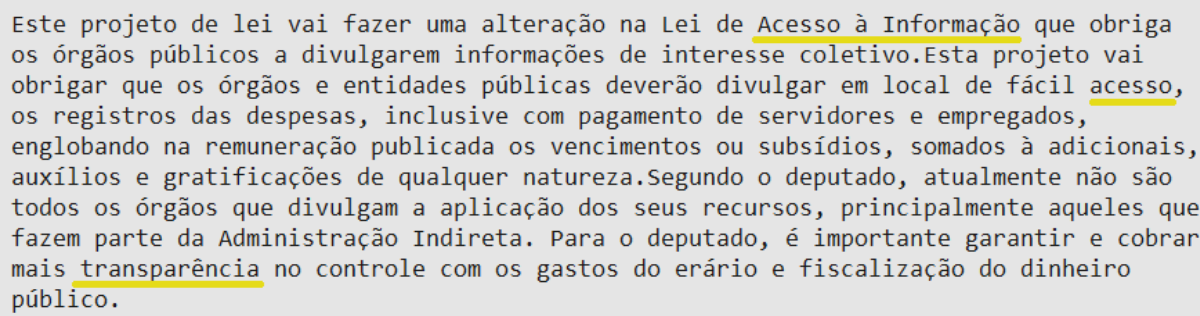

Figura 4. Palavras chaves de transparência no PLS-3497-2015

\section{Tabela 5. Análise de Sentimentos nos comentários do PLS-3497-2015}

\begin{tabular}{|l|c|c|}
\hline \multicolumn{1}{|c|}{ Comentários } & + & - \\
\hline $\begin{array}{l}\text { VÃO LAMBER SABÃO, POLÍTICOS!!.. PAREM DE FERRAR COM A VIDA DAS } \\
\text { EMPRESAS QUE DÃO EMPREGO PARA A POPULAÇÃO!!! }\end{array}$ & 2 & -3 \\
\hline As empresas privadas vão divulgar também? Meu vizinho não precisa saber quanto recebo... & 1 & -3 \\
\hline $\begin{array}{l}\text { Já existe isso, rapá... para de jogar a culpa da robalheira dos políticos em cima dos coitados que } \\
\text { fazem concurso pra trabalhar... }\end{array}$ & 3 & -4 \\
\hline $\begin{array}{l}\text { Por quê não inclui a folha de pagamento dos políticos, inclusive com adicionais, extras, } \\
\text { passagens, hospedagens, auxílios............ }\end{array}$ & 1 & -3 \\
\hline Já não é obrigatório? & 1 & -3 \\
\hline $\begin{array}{l}\text { Deveria obrigar a divulgação do pagamento dos não concursados e o grau de parentesco destes } \\
\text { com administradores, políticos, juízes e ministros. }\end{array}$ & 1 & -3 \\
\hline
\end{tabular}

\subsection{PLS-82-2009}

O PL com título: obrigará as empresas estatais federais a divulgarem, de 3 em 3 meses, as despesas realizadas com publicidade e patrocínio no Diário Oficial da União e em 
jornais de circulação nacional, para aumentar a transparência dos gastos públicos, tem 94\% de aprovação dos cidadãos com 161 votos. A situação atual do PL é: em tramitação. A Fig.5 mostra que o PL demanda principalmente publicidade. Este PL contém 3 comentários, e o SentiStrength qualificou apenas um como negativo. No entanto não seria qualificado com bem negativo por ter apenas -2 (ver Tabela 6.)

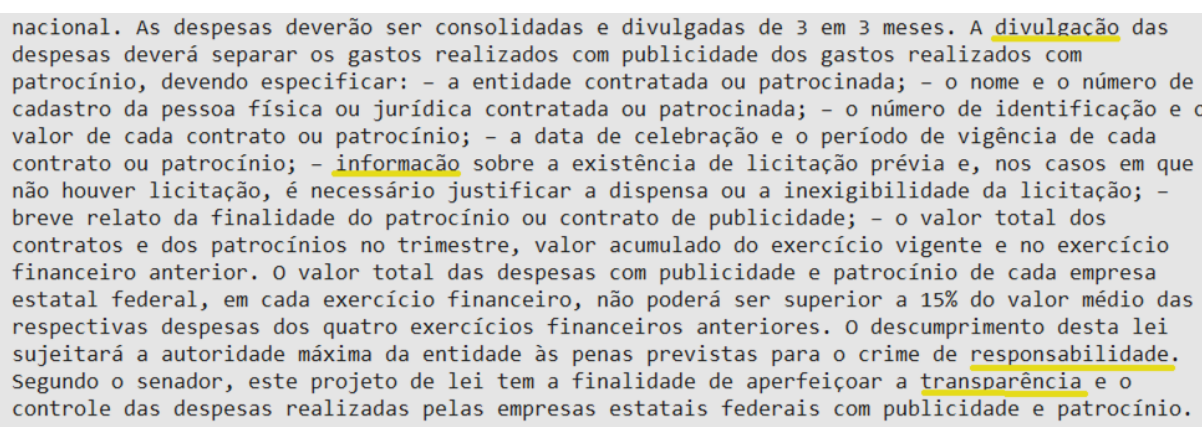

Figura 5. Palavras chaves de transparência no PLS-82-2009

Tabela 6. Análise de Sentimentos nos comentários do PLS-82-2009

\begin{tabular}{|l|c|c|}
\hline \multicolumn{1}{|c|}{ Comentários } & + & - \\
\hline Só na internet já seria o suficiente. Teria um gasto desnecessário de dinheiro indo para os jornais & 1 & -2 \\
\hline
\end{tabular}

\subsection{PLS-387-2011}

O PL com título: Obrigará as universidades públicas e as unidades de pesquisa a criarem arquivos online, de acesso livre, para guardar toda a produção científica dos estudantes, professores, pesquisadores e colaboradores, tem $91 \%$ de aprovação dos cidadãos com 608 votos. A situação atual do PL é em tramitação. Em Fig. 6 mostra-se que o PL demanda principalmente acessibilidade. Dos 15 comentários deste projeto, 2 foram qualificados como bem negativos (ver Tabela 7).

\footnotetext{
(dados sobre os dados da produção científica); - informações que descrevam a produção técnico-científica, a bibliografia, informações relacionadas com as questões de direitos, mantendo-os em acesso restrito enquanto durar a restrição, devendo disponibilizar o acesso ao seu completo teor a partir do momento que acabr a restrição. O depósito deverá oferecer também a possibilidade de o usuário, que tenha interesse em acessar um documento de acesso restrito, solicitar uma cópia deste documento diretamente ao pesquisador por e-mail. As agências de pesquisa e universidades deverão incluir em suas memórias de cálculo o número de artigos publicados em revistas com revisão por pares que foram depositados em depósitos

institucionais, para avaliar a produção científica do pesquisador. Será criado o comitê de alto nível, que será constituído por representantes dos principais segmentos da comunidade científica envolvidos da produção da pesquisa científica, com o objetivo de propor uma política nacional de acesso livre à informação científica, além de estimular professores, pesquisadores e colaboradores a obedecer estar lei, propondo ações e medida que promovam o fluxo da informação científica. Segundo o senador esta medida dará mais visibilidade e transparência aos trabalhos produzidos pelas universidades, promovendo o conhecimento científico e cultural. Ainda de acordo com o deputado, os depósitos institucionais farão com que o governo invista mais em ciência e tecnologia, além de incentivar na elaboração de políticas de promoção de ciência e tecnologia vara o vaís.
}

Figura 6. Palavras chaves de transparência no PLS-387-2011

Tabela 7. Análise de Sentimentos nos comentários do PLS-387-2011

\begin{tabular}{|l|c|c|}
\hline \multicolumn{1}{|c|}{ Comentários } & + & - \\
\hline $\begin{array}{l}\text { Não de acesso livre. Há estudos que envolvem a soberania nacional e não devem ficar expostos a } \\
\text { outros países. }\end{array}$ & 1 & -3 \\
\hline Voto não, pois existem pesquisas confidenciais. & 1 & -3 \\
\hline
\end{tabular}

\subsection{PLC-3305-2008}

O PL com título: Regulamentará a licitação e a contratação de serviços de publicidade por parte da administração pública, tem $84 \%$ de aprovação com 105 votos. A situação 
atual do PL é em tramitação. O PL foi classificado principalmente no grupo de PL's que demandam auditabilidade (ver Fig. 7). Este PL contém 3 comentários, dois quais 2 foram classificados como bem negativos.

passarão a ter de ser licitados por meio de procedimentos autônomos. Para evitar a condução imoral de procedimentos licitatónios, propomos nesse projeto a redefinição da formação das comissões responsáveis pelo processamento e julgamento destas licitações, que obrigatoriamente terão de ser compostas por

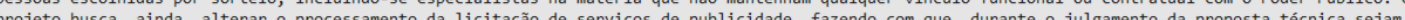
presconhecidos, dos membros da comissão de licitacão, os autores das propostas que serão julgadas. Buscará alterar radicalmente os mecanismos de controle da execucão desses contratos. Passarão a ser exigidos o cadastramento de fornecedores das empresas de publicidade contratadas, a realização de orçamentos prévios, a disponibilização de dados da execucão dos contratos pela rede mundial de computadores, para assegurar-se a transparência e a possibilidade de ampla fiscalização pela sociedade, e a satisfação maior da moralidade administrativa.

Figura 7. Palavras chaves de transparência no PLC-3305-2008

\section{Tabela 8. Análise de Sentimentos nos comentários do PLC-3305-2008}

\begin{tabular}{|l|l|l|}
\hline Comentários & + & - \\
\hline $\begin{array}{l}\text { Administração publica, seja qual for, inclusive empresas estatais não deveriam fazer propaganda. Se } \\
\text { for informação de interesse publico, os jornais, escritos, falados, televisivos fazem sem cobrar nada. }\end{array}$ & & \\
$\begin{array}{l}\text { O dinheiro é do povo e não deve ser gasto com propagandas para enaltecer o partido que estiver no } \\
\text { poder, pois ao final das contas essas propagandas do governo só servem para isso. }\end{array}$ & -3 \\
\hline a regulamentação tem que ser na representação do povo... e não de empresas! & 1 & -3 \\
\hline
\end{tabular}

\subsection{PLC-68-2010}

O PL tem por título: Modificará o sistema de arquivamento dos votos em urnas eletrônicas e os mecanismos de transparência dos votos, e tem $72 \%$ de aprovação dos cidadãos com 184 votos. A situação atual do PL é: em tramitação. $\mathrm{O}$ PL em Fig. 8 demanda acessibilidade. Dos 21 comentários do PL, 11 foram classificados como bem negativos (ver Tabela 9).

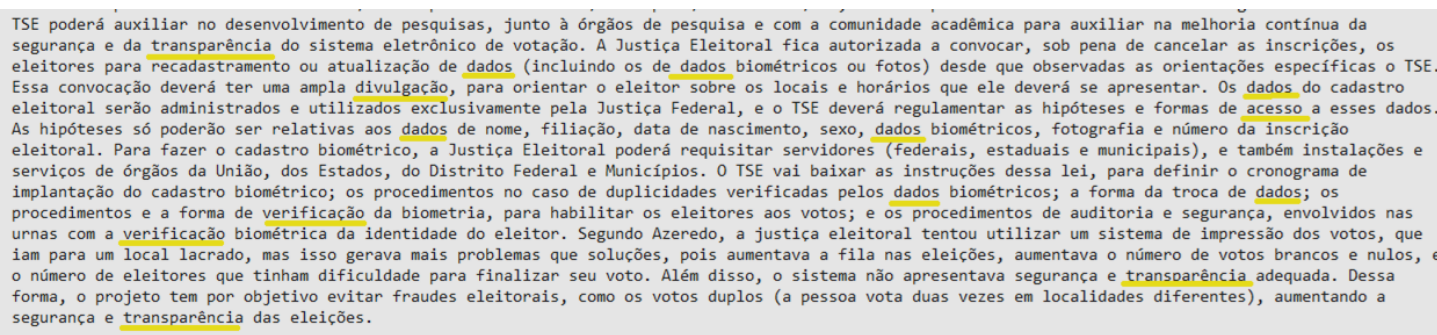

Figura 8. Palavras chaves de transparência no PLC-68-2010

Tabela 9. Análise de Sentimentos nos comentários do PLC-68-2010

\begin{tabular}{|l|c|c|}
\hline \multicolumn{1}{|c|}{ Comentários } & + & - \\
\hline $\begin{array}{l}\text { Imagina que absurdo! Só no Brasil, com uma população alheia a politica, que se permite que uma lei } \\
\text { assim venha a ser proposta. Se esse projeto for aprovado, eles controlarão quem vai ser "eleito" e pronto, } \\
\text { senão, pode nos forçar a votar em determinado candidato, se os nossos dados ficarem vinculados ao voto, } \\
\text { como já é suspeita essa prática lá na Venezuela, onde o governo faz chantagem com o cidadão, } \\
\text { prejudicando sua carreira em função do voto de cabresto. }\end{array}$ & 2 & -3 \\
\hline $\begin{array}{l}\text { Absurda a pretensão do Senador. Compactuar com isso é no mínimo ignorância. Sem conferênciado voto, } \\
\text { não há democracia nem garantia. É o primeiro passo para o fim dos direitos civis. Sem transparência, não } \\
\text { temos eleição! }\end{array}$ & 1 & -3 \\
\hline $\begin{array}{l}\text { São falsos os argumentos do Sen. Azeredo. Ele pretende novamente substituir o voto impresso } \\
\text { CONFERÍVEL pelo eleitor pelo seu voto virtual INCONFERÍVEL pelo eleitor. O voto virtual que o } \\
\text { Azeredo quer recriar elimina totalmente a transparência da apuração, POIS O ELEITOR NÃO TERÁ }\end{array}$ & 2 \\
$\begin{array}{l}\text { COMO CONFERIR se seu voto foi gravado como queria. É um procedimento que não atende ao } \\
\text { Princípio da Independência do Software em sistemas eleitorais que está sendo adotado em todo o mundo. }\end{array}$ & -3 \\
\hline $\begin{array}{l}\text { Azeredo, uma vergonha para nossa democracia, além de Coordenador do Mensalão Mineiro, é agora } \\
\text { criminoso eleitoral, todos os países podem recontar os votos menos o Brasil. O senador tem alguma coisa } \\
\text { contra a transparência? }\end{array}$ & 1 \\
\hline $\begin{array}{l}\text { Mais uma peraltice do Sen. Azarado, que ja devia estar gozando de merecida aposentadoria, em lugar de } \\
\text { se prestar ao triste papel de laranja do TSE. Toda vez que ele se mete a propor leis sobre o que não } \\
\text { entende, e' um desastre. Pois de segurança de dados ele entende menos do que eu, engenheiro eletronico, }\end{array}$ & -3 \\
\hline
\end{tabular}




\begin{tabular}{|c|c|c|}
\hline $\begin{array}{l}\text { entendo de cirurgia cardiaca, e tenta enganar aos incautos, vendendo seu mal intencionado projeto com } \\
\text { justificativas estapafurdias, assopradas sabe-se la' por quem... Ele quer que continue valendo o lema EU } \\
\text { SEI EM QUEM VOTEI. ELES TAMBEM. MAS SO ELES SABEM QUEM RECEBEU O MEU } \\
\text { VOTO... }\end{array}$ & & \\
\hline $\begin{array}{l}\text { Mais uma do velho conhecido Eduardo Azeredo. Ele novamente quer acabar com a possibilidade de } \\
\text { recontagem dos votos. Para esse senador, projetos como ficha limpa e voto impresso são um problema. } \\
\text { Políticos ligados ao Mensalão e à corrupção não querem a transparência e a segurança do processo } \\
\text { eletrônico de votação. Por isso voto não a esse projeto anti- democrático. }\end{array}$ & 2 & -3 \\
\hline $\begin{array}{l}\text { O voto eletrônico é completamente falho. Precisamos de sermos respeitados nas nossas escolhas. Não é } \\
\text { atoa que os outros paises não querem adotar a urma eletrônica e as que adotaram, devolveram. }\end{array}$ & 1 & -3 \\
\hline $\begin{array}{l}\text { O sistema de voto eletronico é totalmente falho e não temos segurança alguma nos nossos votos. Não } \\
\text { sabemos se o nosso voto vai mesmo pro candidato que escolhemos. E o senhor senador sabe bem disso. } \\
\text { Acho que deveria apoiar a etica e a liberdade das pessoas votarem e que sejam respeitados as nossas } \\
\text { escolhas....... os nossos votos. }\end{array}$ & 2 & -3 \\
\hline $\begin{array}{l}\text { O senador define uma solução técnica como projeto de lei. O que ele deveria definir no projeto é o } \\
\text { resultado prático, não a solução técnica, a qual tem de ser estudada por um equipe técnica qualificada para } \\
\text { atender ao requisito prático. }\end{array}$ & 2 & -3 \\
\hline $\begin{array}{l}\text { Não foi esse o que renunciou o cargo de deputado, acusado de mensalão do psdb em minas? sem noção } \\
\text { essa PL. }\end{array}$ & 1 & -3 \\
\hline $\begin{array}{l}\text { Ainda considero o sistema brasileiro falho por conta de não ter sistema de checagem amostral, via } \\
\text { impressão dos votos q deveriam ser depositados em urnas, como é feito em qq país democrático. Causa } \\
\text { estranheza um sistema de votação tão simples e célere não ser adotado por outros países. }\end{array}$ & 2 & -3 \\
\hline
\end{tabular}

\section{Discussão}

A análise de sentimentos, especificamente para a língua portuguesa, tem sido abordada por trabalhos como o SentiMeter-Br (2013), o qual apresenta melhores resultados que o SentiStrength (2012), no entanto o SentiMeter-Br foi desenvolvido para o domínio de Cosméticos. Outro trabalho, PIRPO (2012) é similar aos dois primeiros por utilizar a estratégia baseada em um léxico, contudo o léxico de PIRPO foi realizado para o domínio de Hotéis. Ao melhor do nosso conhecimento o SentiStrength é o único a ter sido validado em várias bases, isto é, comentários de Myspace, Last FM, YouTube, e Flickr entre outros, para extrair um léxico suficientemente robusto para ser aplicado em outros contextos sociais. Aspectos como o tratamento de um corretor ortográfico que não corrige palavras que provavelmente estão escritas de maneira incorreta intencionalmente, um dicionário de emoticons, e o tratamento de palavras que dão uma maior ênfase (strength) fazem com que o SentiStrength seja apropriado para os textos como os comentários de Votenaweb (2009).

Um dos pontos fracos de SentiStrength é o léxico existente em Português, o qual não foi testado. Não se encontrou evidências do processamento de dito léxico. Um bom processamento de léxico, como indicado por Thelwall, (2017), demoraria pelo menos um mês para traduzir para o Português o léxico existente na língua inglesa, a criação de um corpus de 1000 textos previamente classificados por humanos, e o refinamento do léxico com opções da ferramenta através do exame de classificações incorretas no corpus. Por fim, a acurácia desse classificador deveria ser testada em um segundo corpus de textos. Existem outras limitações da ferramenta, mas, no momento, essa nos parece a mais importante para que se possa equiparar seu desempenho com o existente na língua Inglesa.

\section{Resultados}

Para verificar os resultados da análise de sentimentos apresentados na Seção 3, um dos autores fez a verificação manual dos comentários qualificados como bem negativos (de -3 até -5). A Tabela 10 mostra a quantidade de acertos do SentiStrength. Se mostra 
também o grupo ao qual os comentários pertencem segundo a aprovação dos cidadãos. Sim para PL aprovados, Não para PL não aprovados, e Indeciso.

Tabela 10. Acurácia do SentiStrength em classificar comentários negativos (de -3 a -5 )

\begin{tabular}{|c|c|c|c|}
\hline \multirow{2}{*}{} & \multicolumn{3}{|c|}{ Número de comentários de cidadãos que votaram (sim/não/indeciso) nos PLs } \\
\cline { 2 - 4 } & Sim & Indeciso & Não \\
\hline SentiStrength & 18 & 13 & 29 \\
\hline Humano & 5 & 10 & 22 \\
\hline & $27 \%$ & $76 \%$ & $75 \%$ \\
\hline
\end{tabular}

Em Tabela 11 mostramos as palavras do léxico de SentiStrength que estão nos comentários que foram corretamente classificados na tabela 10. Mostra-se também a categorização de léxico que existe na ferramenta.

Tabela 11. Palavras que classificaram corretamente os comentários negativos

\begin{tabular}{|c|c|c|}
\hline \multirow{2}{*}{ SIM } & EmotionLookupTable & Vão [-2], não [-2], superficial [-2], muito[3] \\
\hline & BoosterWordList & Muito[1] \\
\hline \multirow[t]{3}{*}{ NÃO } & EmotionLookupTable & $\begin{array}{l}\text { Vão [-2], não [-2], perda[-2], propaganda[-1], deve[-2], gasto[-2], culpa[-4], } \\
\text { absurdo[-2], chantagem[-3], prejudicando[-3], pretensão[-2], vergonha[-3], } \\
\text { contra[-2], Azarado[-2], triste[-4], desastre[-2], enganar[-2], mal[-3], velho[- } \\
\text { 2] problema[-2] }\end{array}$ \\
\hline & BoosterWordList & deve[-1] \\
\hline & Rule & !!! [+0.6 EmphasisInPunctuation] \\
\hline INDECISO & EmotionLookupTable & não [-2], gasto[-2], simples[-2], Caro[-2], dúvida[-2] \\
\hline
\end{tabular}

Sobre os falsos positivos, verificou-se que vários comentários foram classificados como negativos por conter apenas a palavra não [-2]. Temos outros casos onde a ferramenta falhou:

Comentário no PLC-1080-2011 que tem -4 e não é negativo:

Embora falte lapidar este projeto, pois poderiam agilizar o processo de informação, acredito que será um passo para diminuirmos o maior câncer [-3] deste, ou seja, a Corrupção [-1]!!!

Comentário no PLC-68-2010 que por ter escrito Azarado em vez de Azeredo foi mais negativo:

Mais uma peraltice do Sen. Azarado, que já devia estar gozando de merecida aposentadoria, em lugar de se prestar ao triste papel de laranja do TSE....

Outros comentários têm palavras informais do português que não estão no léxico: enrolar, xingarem, ferrar, roubalheira, rapaz. As duas últimas se acharam mal escritas nos comentários como: robalheira e rapá. Outro exemplo é a palavra apenas que não se encontra no léxico, mas aparece significativamente na amostra utilizada.

\section{Conclusão}

Este trabalho teve como objetivo verificar a eficácia de SentiStrength aplicado ao contexto de Projetos de Lei relacionados à Transparência. Os resultados têm boa acurácia nos grupos de comentários negativos e indecisos, no entanto no grupo de comentários positivos (a favor do PL) o SentiStrength qualifica como negativo vários comentários por conter apenas a palavra não. Como trabalhos futuros, vemos que é possível realizar a estratégia proposta por Thelwall (2017) para treinamento no contexto específico, dado que os comentários no VotenaWeb já estão classificados (voto sim, não, indeciso) com o qual é possível recuperar os 1000 itens recomendados para 
treinamento. Outro trabalho é evoluir o léxico em Português utilizando o conceito do LAL (Léxico Ampliado da Linguagem) (Engiel et al., 2015).

Segundo as informações de VotenaWeb (2009)², nenhum dos 8 PLs, com vários indicadores de demanda de transparência, já se transformou em Lei. Acreditamos que a estratégia apresentada poderia ajudar a filtrar os comentários dos cidadãos, para que os congressistas possam se apropriar da demanda que está sendo expressa em redes sociais, no caso tomando o Votenaweb como fonte.

\section{Referências}

Engiel, P., Portugal, R.L.Q., do Prado Leite, J. C. S. Descobrindo projetos de lei relacionados a transparência. IV Workshop de Transparência em Sistemas, Rio de Janeiro - RJ, Brasil. (2016)

Portugal, R. L. Q., Engiel, P., \& do Prado Leite, J. C. S. (2017a). Existe uma Demanda de Transparência? Análise de comentários à Projetos de Lei. In V Workshop de Transparência em Sistemas. São Paulo, Brasil.

Thelwall, M., Buckley, K., \& Paltoglou, G. (2012). Sentiment strength detection for the social web. Journal of the Association for Information Science and Technology, 63(1), 163-173.

SentiStrength Tool, 2018. Em (http://sentistrength.wlv.ac.uk). Acessado em 02/04/2018.

Chung, L., \& do Prado Leite, J. C. S. (2009). On non-functional requirements in software engineering. In Conceptual modeling: Foundations and applications (pp. 363-379). Springer, Berlin, Heidelberg.

ER - PUC-Rio, 2013. Disponível em (http://transparencia.inf.pucrio.br/wiki/index.php/Catálogo_Transparência). Acessado em 20/03/2017.

Portugal, R. L. Q., Engiel, P., Roque, H., \& do Prado Leite, J. C. S. (2017b). Is There a Demand of Software Transparency? In Proceedings of the 31st Brazilian Symposium on Software Engineering (pp. 204-213). ACM.

Votenaweb, 2009. Disponível em (http://www.votenaweb.com.br/). Ac. Em 02/04/2018

Thelwall, M. (2017). The Heart and soul of the web? Sentiment strength detection in the social web with SentiStrength. In Cyberemotions (pp. 119-134). Springer, Cham.

Rosa, R. L., Rodriguez, D. Z., \& Bressan, G. (2013). SentiMeter-Br: A new social web analysis metric to discover consumers' sentiment. In Consumer Electronics (ISCE), 2013 IEEE 17th International Symposium on (pp. 153-154). IEEE.

Chaves, M. S., de Freitas, L. A., Souza, M., \& Vieira, R. (2012). Pirpo: An algorithm to deal with polarity in portuguese online reviews from the accommodation sector. In International Conference on Application of Natural Language to Information Systems (pp. 296-301). Springer, Berlin, Heidelberg.

Engiel, P., Pivatelli, J., Moura, P., Portugal, R. L. Q., \& do Prado Leite, J. C. S. (2015). Um processo colaborativo para a construção de léxicos: o caso da divulgação de transparência. In WER.

\footnotetext{
${ }^{2} \mathrm{Em} 02 / 04 / 2018$
} 